Original Research

\title{
Exploring the Effects of Aerobic Exercise on Blood Coagulability in Caregivers of Patients with Dementia: A Randomized Controlled Trial
}

Akemi Hirano ${ }^{1,{ }^{*}}$, Yusuke Suzuki ${ }^{2}$, Hiroyuki Umegaki ${ }^{3}$, Toshio Hayashi ${ }^{4}$, Koichiro Ina ${ }^{5}$, Joji Onishi ${ }^{3}$, Jun Hasegawa ${ }^{6}$, Masafumi Kuzuya ${ }^{3,7}$

1. Department of Adult Nursing, Shubun University, Faculty of Nursing, 6 Nikko-cho, Ichinomiya, Aichi 491-0938, Japan; E-Mail: hirano@med.nagoya-u.ac.jp

2. Center for Community Liaison and Patient Consultations, Nagoya University Hospital, 65 Tsuruma, Showa, Nagoya, Aichi 466-8550, Japan; E-Mail: yus@med.nagoya-u.ac.jp

3. Department of Community Healthcare \& Geriatrics, Nagoya University Graduate School of Medicine, 65 Tsuruma, Showa, Nagoya, Aichi 466-8550, Japan; E-Mails: umegaki@med.nagoyau.ac.jp; j-onishi@med.nagoya-u.ac.jp; kuzuya@med.nagoya-u.ac.jp

4. Department of Geriatrics, Nagoya University Graduate School of Medicine, School of Health Sciences, Daiko-Minami, Higashi-ku, Nagoya, Aichi 461-8673, Japan; E-Mail: hayashi@med.nagoya-u.ac.jp

5. Internal Medicine, Ina Clinic, 3-111 Hirabari, Tenpaku, Nagoya, Aichi 468-0011, Japan; E-Mail: kzinana@yahoo.co.jp

6. Internal Medicine, Nagoya Teishin Hospital, 2-2-5 Izumi, Higashi, Nagoya, Aichi 461-8798, Japan; E-Mail: hasejun@med.nagoya-u.ac.jp

7. Institute of Innovation for Future Society, Nagoya University, 65 Tsuruma, Showa, Nagoya, Aichi 466-8550, Japan

* Correspondence: Akemi Hirano; E-Mail: hirano@med.nagoya-u.ac.jp

Academic Editor: James S. Powers

Special Issue: Models of Caregiver Support

OBM Geriatrics

2020, volume 4, issue 1

doi:10.21926/obm.geriatr.2001108
Received: October 13, 2019

Accepted: February 11, 2020

Published: February 19, 2020

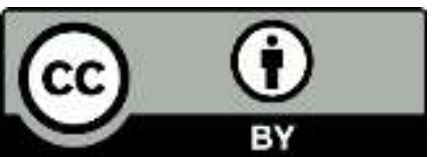

(C) 2020 by the author. This is an open access article distributed under the conditions of the Creative Commons by Attribution License, which permits unrestricted use, distribution, and reproduction in any medium or format, provided the original work is correctly cited. 


\begin{abstract}
The incidence of vascular diseases among caregivers of dementia patients is high, and one potential cause is the exacerbation of blood coagulability due to mental strain from caregiving. This study aimed to examine the effects of aerobic exercise on blood coagulability, from the perspective of improving the health of caregivers. Thirty-one healthy elderly caregivers, residing with patients suffering from Alzheimer's-type dementia, were randomly divided into two groups. In the intervention group, moderate walking exercises (3 METs) were implemented. This group displayed a trend toward lower D-dimer levels, with no statistical significance $(p=0.05)$. Also, the Mini-Mental State Examination (MMSE) scores of the dementia patients remained unchanged. In the control group, the levels of von Willebrand factor antigen fell significantly $(p<0.05)$. However, the D-dimer levels remained unchanged and the MMSE scores of the patients significantly decreased following the observation period $(p<0.05)$. Our findings suggest the need to develop effective methods to maintain, promote, and advance the health of caregivers of dementia patients.
\end{abstract}

\title{
Keywords
}

Aerobic exercise; caregiver burden; D-dimer; dementia; MMSE

\section{Introduction}

Caregivers for dementia patients tend to experience a larger burden than that by the caregivers for patients with other physical illnesses [1]. This is likely due to the stresses caused by the psychological and behavioral symptoms that are unique to dementia. Additionally, these caregivers have been reported to experience chronic exhaustion [2], hypertension [3], and ischemic heart disease [4]. The mortality risk in caregivers, who experienced a psychological and physical sense of burden, increased by $63 \%$ after four years, with a $1.63-$ fold greater relative risk [5].

Mental stress has been shown to trigger a hypercoagulable state as evidenced by increases in the thrombin-antithrombin complex (TAT) and D-dimer levels [6]. D-dimer is associated with parameters of the blood coagulation system, suggesting that D-dimer levels correlate with atherothrombosis [7]. Thrombus formation due to unbalanced coagulability is strongly implicated in ischemic heart disease [8], with exacerbated blood coagulability leading to coronary heart disease. Some studies have reported that caregivers of dementia patients have higher blood coagulability compared to non-caregivers [9]. This may suggest that the mental stress that accompanies caregiving exacerbates blood coagulability and increases the incidence of thrombotic disorders. Coronary heart disease has several known risk factors-fibrinogen, white blood cell count, factor VIII, and von Willebrand factor-elevated levels of which act as indicators of the disease. They may also play causative roles in coronary heart disease.

In general, elderly caregivers engage in little physical activity [10] and lack sufficient time for rest or exercise [11]. Low levels of physical activity can increase the risk of hypertension and cardiovascular disease [12]; the mortality rate among such elderly people is reportedly high [13]. Exercise may reduce the thrombotic activity of platelets as well as that of the coagulation system, resulting in an improved hemostatic balance [14]. Research in exercise therapy has found that 
aerobic exercise lowers blood coagulability in healthy individuals and patients with cardiovascular conditions [15]. Additionally, habitual physical exercise may affect not only the physical function but also the mental state of such individuals [16].

Many intervention studies targeting caregivers of dementia patients report that mental support and educational activities may reduce the sense of caregiver burden. For example, counseling relieved depression [17], using telephone improved quality of life [18], and holding educational sessions relevant to the condition or therapy lessened the sense of burden associated with caregiving [19].

We hypothesized that aerobic exercise can attenuate the exacerbation of blood coagulability in elderly caregivers of dementia patients. To test this hypothesis, we implemented a feasible aerobic exercise routine among caregivers of dementia patients residing at home. We, then, examined the effects of exercise on blood coagulability and evaluated whether exercise therapy contributes to reducing the risk of disease.

\section{Materials and Methods}

\subsection{Methods}

\subsubsection{Subjects}

We conducted a survey of 50 caregivers residing with patients suffering from senile dementia of Alzheimer's type, between ages 65 and 80 . These patients were diagnosed by geriatric physicians and met the DSM-IV diagnostic criteria [20]. While the focus of the study was healthy caregivers, we also included those with chronic diseases, such as hypertension, diabetes, and dyslipidemia, under control with periodic treatment at medical facilities. Nevertheless, we excluded the caregivers with a previous history of cerebrovascular disease, such as stroke or myocardial infarction, or liver disease, and those with preexisting exercise habits (exercising twice a week for 30 min or more per session).

The Ethics Committee of Nagoya University Graduate School of Medicine approved this study. The participants provided informed consent in writing. We took appropriate ethical measures, such as clarifying that their participation was voluntary.

\subsubsection{Study Design}

Participants were randomly assigned to one of two groups-Intervention or Control group. The intervention group performed moderate exercise for 12 weeks, which involved walking for 30 min per session while maintaining a normal walking speed (3 METs) [21] three times a week. Since participants were elderly caregivers, we limited the physical activity level to 3 METs. Moreover, we adopted aerobic exercise as our choice of activity, given the ease of incorporating it into the daily routine of individuals. The control group was instructed to continue their usual routines. A pedometer and a record sheet were distributed to all the participants. Participants in the intervention group recorded their own state of compliance with the exercise program. These were collected after the observation period and analyzed. 


\subsubsection{Caregiver Factors}

To assess blood coagulability, we examined levels of four factors-(i) von Willebrand factor (VWF) antigen, which plays an important role in hemostasis, (ii) D-dimer, a protein fragment generated when blood clots break down, (iii) thrombin-antithrombin III complex (TAT), which promotes blood clotting, and (iv) tissue plasminogen activator/plasminogen activator inhibitor type 1 (tPA/PAI-1) complex, which functions during blood clotting and when blood clots break down. These factors reflect the control of thrombus growth in blood vessels based on a balance between the coagulation and fibrinolytic systems. Higher levels of these factors indicate a greater degree of exacerbation of blood coagulability [22]. In fact, high levels of the tPA/PAI-1 complex were observed in patients with vascular disease [23].

\subsubsection{Scale for Dementia Patients}

The cognitive function of dementia patients was assessed before and after the observation period, using the Mini-Mental State Examination (MMSE) (Japanese language version) [24].

\subsubsection{Statistical Analysis}

Statistical analyses were conducted using the SPSS software (version 25.0). The Mann-Whitney $U$ test was applied to compare the background characteristics of control and intervention groups at baseline (Table 1). The Wilcoxon test was used for baseline and post-intervention comparisons in both groups (Table 2). The Mann-Whitney $U$ test was used to compare rates of change after the intervention between the two groups (Table 3).

Table 1 Participant characteristics.

\begin{tabular}{|c|c|c|c|c|c|}
\hline \multirow[b]{2}{*}{ Caregivers } & \multicolumn{2}{|c|}{ Intervention Group ( $\mathrm{N}=17)$} & \multicolumn{2}{|c|}{ Control group $(\mathrm{N}=14)$} & \multirow[b]{2}{*}{$P$} \\
\hline & Median & IQR & Median & IQR & \\
\hline Sex (Male/Female) (n) & $6 / 11$ & & $4 / 10$ & & 0.769 \\
\hline Age (years) & 73.0 & $69.0-76.0$ & 76.5 & $73.5-78.0$ & 0.071 \\
\hline $\begin{array}{l}\text { Caregiving period } \\
\text { (months) }\end{array}$ & 37.0 & $14.0-53.5$ & 26.5 & $14.8-60.0$ & 1.000 \\
\hline $\begin{array}{l}\text { Caregiving time } \\
\text { (hrs/day) }\end{array}$ & 8.0 & $3.0-15.5$ & 15.5 & $5.3-16.3$ & 0.128 \\
\hline vWF antigen (\%) & 138.0 & $112.5-163.0$ & 168.5 & $117.5-255.3$ & 0.128 \\
\hline D-dimer $(\mu \mathrm{g} / \mathrm{mL})$ & 0.34 & $0.26-0.45$ & 0.36 & $0.23-0.71$ & 0.860 \\
\hline TAT (ng/mL) & 2.10 & $1.25-2.45$ & 1.60 & $1.28-2.48$ & 0.769 \\
\hline tPA-PAI (ng/mL) & 6.30 & $4.55-9.05$ & 6.45 & $4.15-8.13$ & 0.681 \\
\hline Pulse (beats/min) & 80.0 & $66.0-80.0$ & 80.0 & $69.0-80.0$ & 0.830 \\
\hline $\begin{array}{l}\text { Systolic blood } \\
\text { pressure }(\mathrm{mmHg})\end{array}$ & 132.0 & $124.0-141.0$ & 120.0 & $110.0-129.0$ & $0.044^{*}$ \\
\hline $\begin{array}{l}\text { Diastolic blood } \\
\text { pressure }(\mathrm{mmHg})\end{array}$ & 80.0 & $70.0-88.0$ & 74.0 & $70.0-80.0$ & 0.493 \\
\hline $\mathrm{BMI}$ & 22.6 & $19.6-23.8$ & 22.0 & $19.2-23.9$ & 0.830 \\
\hline
\end{tabular}


Hypertension (number of patients)

Diabetes (number of patients)
9

4
5

4
0.421

0.830

\section{Patients}

$\begin{array}{llllll}\text { Age (years) } & 74.0 & 71.0-79.5 & 79.0 & 75.8-82.0 & 0.084 \\ \text { MMSE score } & 24.0 & 20.5-26.5 & 21.5 & 20.8-25.0 & 0.315\end{array}$

ns: not significant; ${ }^{*}: p<0.05 ;{ }^{* *}: p<0.01$; Data are presented as median and interquartile range (IQR). vWF antigen, von Willebrand factor antigen; TAT, thrombin-antithrombin III complex; tPA-PAI, tissue plasminogen activator/plasminogen activator inhibitor type 1 complex; MMSE, Mini-Mental State Examination.

Table 2 Comparison of parameters (changes in values) over the observation period.

\begin{tabular}{lcccc}
\hline Caregivers & \multicolumn{2}{c}{ Intervention Group $(\mathrm{N}=17)$} & \multicolumn{2}{c}{ Control Group (N=14) } \\
\hline & $\begin{array}{l}\text { Median } \\
\text { change }\end{array}$ & $p$ & $\begin{array}{l}\text { Median } \\
\text { change }\end{array}$ & $p$ \\
\hline vWF antigen $(\%)$ & -6.00 & 0.73 & -15.50 & $0.03^{*}$ \\
D-dimer $(\mu \mathrm{g} / \mathrm{mL})$ & -0.08 & 0.05 & -0.05 & 0.83 \\
TAT $(\mathrm{ng} / \mathrm{mL})$ & -0.30 & 0.68 & 0.15 & 0.40 \\
tPA-PAI $(\mathrm{ng} / \mathrm{mL})$ & 0.20 & 0.91 & -0.20 & 0.75 \\
\hline
\end{tabular}

\section{Patients}

MMSE score $-1.00$ 0.26 $-4.0$ $0.01^{*}$

Change after intervention $=$ Post-intervention value-baseline value. ${ }^{*}: p<0.05 ; * *: p<0.01$. vWF antigen, von Willebrand factor antigen; TAT, thrombin-antithrombin III complex; tPA-PAI, tissue plasminogen activator/plasminogen activator inhibitor type 1 complex; MMSE, Mini-Mental State Examination.

Table 3 Comparison of parameters (rates of change) over the observation period.

\begin{tabular}{lccccc}
\hline Caregivers & \multicolumn{2}{c}{ Intervention Group (N=17) } & \multicolumn{2}{c}{ Control Group (N=14) } & $p$ \\
\hline $\begin{array}{l}\text { Median rate of } \\
\text { change (\%) }\end{array}$ & IQR & $\begin{array}{c}\text { Median rate of } \\
\text { change (\%) }\end{array}$ & IQR & \\
\hline vWF antigen & 0.00 & -14.26 .5 & -4.6 & -17.61 .65 & 0.173 \\
D-dimer & -20.0 & -37.26 .2 & -4.6 & -23.516 .1 & 0.377 \\
TAT & -4.2 & -31.038 .0 & 3.85 & -14.930 .2 & 0.518 \\
tPA-PAI & -2.1 & -16.225 .3 & 0.00 & -16.217 .6 & 0.922 \\
\hline Patients & & & & & \\
\hline MMSE score & -5.4 & -29.27 .1 & -12.9 & $-27.5-3.75$ & 0.353 \\
\hline
\end{tabular}

Rates of change after intervention (\%) $=($ Post-intervention value-baseline value)/baseline value $\times 100 . *$ : $\mathrm{p}<0.05{ }^{* *}$ : $p<0.01$. vWF antigen, von Willebrand factor antigen; TAT, thrombin-antithrombin III complex; tPA-PAI, tissue plasminogen activator/plasminogen activator inhibitor type 1 complex; MMSE, Mini-Mental State Examination. 


\section{Results}

Of the 50 participants, 11 met the exclusion criteria and three refused to participate. Five participants dropped out of the study, during the observation period. The reason for refusal or dropping out was the lack of spare time due to the demands of caregiving and daily life. Consequently, we assigned 17 participants to the intervention group and 14 to the control group.

Table 1 summarizes the background characteristics of participants at baseline. Only systolic blood pressure differed significantly between the intervention and control groups. The baseline levels of blood coagulation factors displayed no significant differences. The daily number of steps was significantly larger $(p<0.01)$ in the intervention group (median: 9204.0; IQR: 7660.9 to 10242.1 ) compared to the control group (median: 5877.4; IQR: 3128.8 to 7317.4). Table 2 displays the changes in values measured from the baseline. With respect to blood coagulability in the intervention group, we observed a trend toward lower D-dimer levels; but this was not statistically significant $(p=0.05)$. MMSE scores of the dementia patients remained the same after an intervention. In contrast, VWF antigen levels in the control group decreased significantly $(p<0.05)$, and MMSE scores of the patients also decreased significantly $(p<0.05)$ after the observation period. Table 3 shows the rates of change after the intervention in both groups. The median rate of change in D-dimer level was $-20 \%$ (IQR: -37.2 to 6.2 ) in the intervention group, with no significant difference compared to the control group ( $p=0.377$ ). The median rates of change in VWF antigen levels were $0.00 \%$ (IQR: -14.2 to 6.5 ) and $-4.6 \%$ (IQR: -17.6 to 1.65 ) in the intervention and control groups, respectively, with no significant differences between the two groups $(p=0.173)$.

\section{Discussion}

In this study, aerobic exercise failed to demonstrate lowered blood coagulability in caregivers of dementia patients.

\subsection{Effects of Exercise Program}

Moderately strenuous exercise is reportedly easier to sustain than highly strenuous exercise [25]. In our study, we exhibited that an intervention program incorporating moderately strenuous exercises is sustainable in elderly participants for a relatively short period. Awareness of health management likely increased in participants, making it possible for them to sustain the activities. This suggests that aerobic exercise is relatively easy to incorporate into the lives of caregivers of patients with dementia.

\subsection{Changes in Blood Coagulability Due to Exercise}

In Prior studies on blood coagulability immediately after exercise demonstrated no change in healthy subjects [26], but research on stroke patients displayed improvements [27]. This suggests that exercise may have a greater effect on people with exacerbated blood coagulability. In the present study, there was a mild trend toward a lowered D-dimer in intervention subjects, but with no significant change. One possible reason could be that, unlike the stroke patients, participants of our study did not exhibit any progression of arteriosclerosis. 
The VWF antigen levels significantly decreased in the control group, which differed from the previous reports suggesting that VWF antigen levels rise in response to psychological stress [28]. While the reason for this discrepancy is unclear, baseline VWF antigen levels were somewhat higher in this small control group compared to the intervention group. During the study, participants in the control group took a median of 5877.4 (IQR: 3128.8 to 7317.4) steps a day. This indicates that the caregivers walk a great deal in their daily lives, reflecting a high level of physical activity associated with caregiving.

In summary, our findings concluded that aerobic exercises do not always positively impact the health of caregivers. However, there is a possibility of large variations in the overall physical stamina and strength of individuals in our study population as well as age-related changes in motor functions. Furthermore, in both groups, there were variations in the level of physical activity based on the number of steps taken. This highlights the need to increase the sample population size and to develop new methods/tests to assess effects of activity. To accurately assess the effects of exercise programs, long-term follow-up studies will be needed, with exercise prescribed in a way that is tailored to the health state of each caregiver.

\section{Acknowledgements}

We thank everyone who participated in this study, as well as the patients and family members for their cooperation.

\section{Author Contributions}

Akemi Hirano and Hiroyuki Umegaki conceived the idea and designed this study. Akemi Hirano carried out data analysis and interpretation. Akemi Hirano wrote the first draft and Yusuke Suzuki, Hiroyuki Umegaki and Koichiro Ina critically discussed all the versions of the manuscript, and appraised the final version prior to submission.

Yusuke Suzuki, Hiroyuki Umegaki, Toshio Hayashi, Koichiro Ina, Joji Onishi, Jun Hasegawa and Masafumi Kuzuya recruited the participants and Hiroyuki Umegaki contributed to the overall supervision of the present study.

\section{Competing Interests}

The authors declare no conflicts of interest.

\section{References}

1. Muraki I, Yamagishi K, Ito Y, Fujieda T, Ishikawa Y, Miyagawa Y, et al. Caregiver burden for impaired elderly Japanese with prevalent stroke and dementia under long-term care insurance system. Cerebrovasc Dis. 2008; 25: 234-240.

2. Onishi J, Suzuki Y, Umegaki H, Nakamura A, Endo H, Iguchi A. Influence of behavioral and psychological symptoms of dementia (BPSD) and environment of care on caregivers' burden. Arch Gerontol Geriatr. 2005; 41: 159-168.

3. Shaw WS, Patterson TL, Ziegler MG, Dimsdale JE, Semple SJ, Grant I. Accelerated risk of hypertensive blood pressure recordings among Alzheimer caregivers. J Psychosom Res. 1999; 46: 215-227. 
4. Mausbach BT, Patterson TL, Rabinowitz YG, Grant I, Schulz R. Depression and distress predict time to cardiovascular disease in dementia caregivers. Health Psychol. 2007; 26: 539-544.

5. Schulz R, Beach SR. Caregiving as a risk factor for mortality: The caregiver health effects study. JAMA. 1999; 282: 2215-2219.

6. von Känel R, Dimsdale JE, Adler KA, Patterson TL, Mills PJ, Grant I. Effects of depressive symptoms and anxiety on hemostatic responses to acute mental stress and recovery in the elderly. Psychiatry Res. 2004; 126: 253-264.

7. Tataru MC, Heinrich J, Junker R, Schulte H, Von Eckardstein A, Assmann G, et al. D-dimers in relation to the severity of arteriosclerosis in patients with stable angina pectoris after myocardial infarction. Eur Heart J. 1999; 20: 1493-1502.

8. Folsom AR, Wu KK, Rosamond WD, Sharrett AR, Chambless LE. Prospective study of hemostatic factors and incidence of coronary heart disease: The atherosclerosis risk in communities (ARIC) study. Circulation. 1997; 96: 1102-1108.

9. von Känel R, Dimsdale JE, Adler KA, Patterson TL, Mills PJ, Grant I. Exaggerated plasma fibrin formation (D-dimer) in elderly Alzheimer caregivers as compared to noncaregiving controls. Gerontology. 2005; 51: 7-13.

10. Wilcox S, Castro C, King AC, Housemann R, Brownson RC. Determinants of leisure time physical activity in rural compared with urban older and ethnically diverse women in the United States. J Epidemiol Community Health. 2000; 54: 667-672.

11. Burton LC, Newsom JT, Schulz R, Hirsch CH, German PS. Preventive health behaviors among spousal caregivers. Prev Med. 1997; 26: 162-169.

12. Blair SN, Kohl HW, Paffenbarger RS, Clark DG, Cooper KH, Gibbons LW. Physical fitness and allcause mortality: A prospective study of healthy men and women. JAMA. 1989; 262: 23952401.

13. Stessman J, Hammerman-Rozenberg R, Cohen A, Ein-Mor E, Jacobs JM. Physical activity, function, and longevity among the very old. Arch Intern Med. 2009; 169: 1476-1483.

14. Sinzinger $\mathrm{H}$, Virgolini I. Effects of exercise on parameters of blood coagulation, platelet function and the prostaglandin system. Sports Med. 1988; 6: 238-245.

15. Womack CJ, Nagelkirk PR, Coughlin AM. Exercise-induced changes in coagulation and fibrinolysis in healthy populations and patients with cardiovascular disease. Sports Med. 2003; 33: 795-807.

16. Leppämäki SJ, Partonen TT, Hurme J, Haukka JK, Lönnqvist JK. Randomized trial of the efficacy of bright-light exposure and aerobic exercise on depressive symptoms and serum lipids. The J Clin Psychiatry. 2002; 63: 316-321.

17. Gaugler JE, Roth DL, Haley WE, Mittelman MS. Can counseling and support reduce burden and depressive symptoms in caregivers of people with Alzheimer's disease during the transition to institutionalization? Results from the New York University caregiver intervention study. J Am Geriatr Soc. 2008; 56: 421-428.

18. Belle SH, Burgio L, Burns R, Coon D, Czaja SJ, Gallagher-Thompson D, et al. Enhancing the quality of life of dementia caregivers from different ethnic or racial groups: A randomized, controlled trial. Ann Intern Med. 2006; 145: 727-738.

19. Gavrilova SI, Ferri CP, Mikhaylova N, Sokolova O, Banerjee S, Prince M. Helping carers to care-the 10/66 dementia research group's randomized control trial of a caregiver intervention in Russia. Int J Geriatr Psychiatry. 2009; 24: 347-354. 
20. American Psychiatric Association. Diagnostic and statistical manual of mental disorders. 4th ed. Washington, DC: American Psychiatric Association; 2000.

21. Thompson PD, Buchner D, Piña IL, Balady GJ, Williams MA, Marcus BH, et al. Exercise and physical activity in the prevention and treatment of atherosclerotic cardiovascular disease: $\mathrm{A}$ statement from the Council on Clinical Cardiology (Subcommittee on Exercise, Rehabilitation, and Prevention) and the Council on Nutrition, Physical Activity, and Metabolism (Subcommittee on Physical Activity). Circulation. 2003; 107: 3109-3116.

22. Neyrinck AP, Liu KD, Howard JP, Matthay MA. Protective mechanisms of activated protein $C$ in severe inflammatory disorders. Br J Pharmacol. 2009; 158: 1034-1047.

23. Tóth NK, Csanádi Z, Hajas O, Kiss A, Nagy-Baló E, Kovács KB, et al. Intracardiac hemostasis and fibrinolysis parameters in patients with atrial fibrillation. Biomed Res Int. 2017; doi: $10.1155 / 2017 / 3678017$.

24. Folstein MF, Folstein SE, McHugh PR. "Mini-mental state": A practical method for grading the cognitive state of patients for the clinician. J Psychiatr Res. 1975; 12: 189-198.

25. Dishman RK. Exercise adherence. Champaign, IL: Human Kinetics Publishers; 1988.

26. Hegde SS, Goldfarb AH, Hegde S. Clotting and fibrinolytic activity change during the $1 \mathrm{~h}$ after a submaximal run. Med Sci Sports Exerc. 2001; 33: 887-892.

27. Ivey FM, Womack CJ, Kulaputana O, Dobrovolny CL, Wiley LA, Macko RF. A single bout of walking exercise enhances endogenous fibrinolysis in stroke patients. Med Sci Sports Exerc. 2003; 35: 193-198.

28. Hamer M, Williams E, Vuonovirta R, Giacobazzi P, Gibson EL, Steptoe A. The effects of effortreward imbalance on inflammatory and cardiovascular responses to mental stress. Psychosom Med. 2006; 68: 408-413.

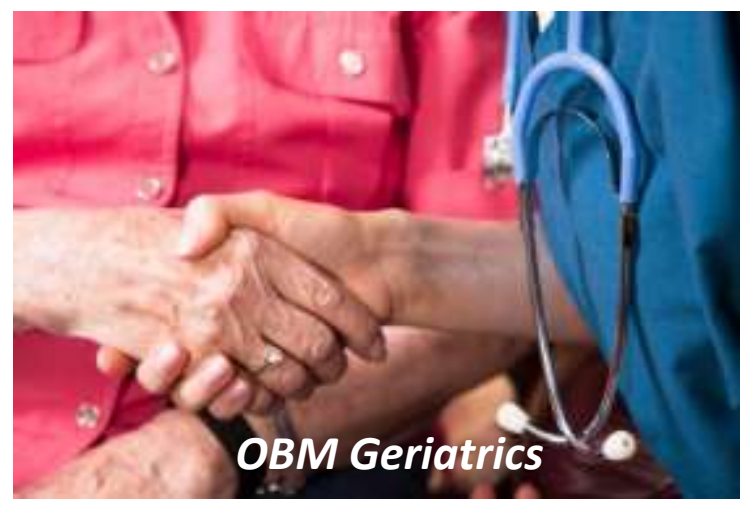

Enjoy OBM Geriatrics by:

1. Submitting a manuscript

2. Joining in volunteer reviewer bank

3. Joining Editorial Board

4. Guest editing a special issue

For more details, please visit: http://www.lidsen.com/journals/geriatrics 